\title{
Integral quantification of seasonal soil moisture changes in farmland by cosmic-ray neutrons
}

\author{
C. A. Rivera Villarreyes, G. Baroni, and S. E. Oswald \\ Institute of Earth and Environmental Science, University of Potsdam, Karl-Liebknecht-Strasse 24-25, \\ 14476 Potsdam, Germany
}

Received: 4 July 2011 - Published in Hydrol. Earth Syst. Sci. Discuss.: 14 July 2011

Revised: 9 December 2011 - Accepted: 13 December 2011 - Published: 21 December 2011

\begin{abstract}
Soil moisture at the plot or hill-slope scale is an important link between local vadose zone hydrology and catchment hydrology. However, so far only a few methods are on the way to close this gap between point measurements and remote sensing. One new measurement methodology that could determine integral soil moisture at this scale is the aboveground sensing of cosmic-ray neutrons, more precisely of ground albedo neutrons. The present study performed ground albedo neutron sensing (GANS) at an agricultural field in northern Germany. To test the method it was accompanied by other soil moisture measurements for a summer period with corn crops growing on the field and a later autumn-winter period without crops and a longer period of snow cover. Additionally, meteorological data and aboveground crop biomass were included in the evaluation. Hourly values of ground albedo neutron sensing showed a high statistical variability. Six-hourly values corresponded well with classical soil moisture measurements, after calibration based on one reference dry period and three wet periods of a few days each. Crop biomass seemed to influence the measurements only to minor degree, opposed to snow cover which has a more substantial impact on the measurements. The latter could be quantitatively related to a newly introduced field neutron ratio estimated from neutron counting rates of two energy ranges. Overall, our study outlines a procedure to apply the ground albedo neutron sensing method based on devices now commercially available, without the need for accompanying numerical simulations and suited for longer monitoring periods after initial calibration.
\end{abstract}

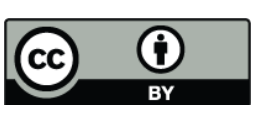

Correspondence to:

C. A. Rivera Villarreyes

(crivera@uni-potsdam.de)

\section{Introduction}

Soil moisture plays an important role in the hydrological cycle. It influences climate and weather (Wu and Dickinson, 2004), and also determines surface runoff after precipitation events and controls groundwater recharge. In addition, soil moisture is a key factor for chemistry, biology, infiltration and matter transport processes in soil, e.g. it provides the main storage of water available for vegetation (Robinson et al., 2008). Despite the importance of soil moisture, its representative measurement is still a big challenge in hydrological research. Observation techniques of soil moisture have improved at various scales. Measurements of soil moisture at the point-scale $\left(\sim 1 \mathrm{dm}^{3}\right)$ have advanced significantly in the last decades for a wide range of sensors. These are usually the basis for calculation of water storage and its changes at the field scale (up to $1 \mathrm{~km}^{2}$ ). Point measurements are scaled up to large areas applying geostatistical techniques (Western et al., 2002; Bogena et al., 2010). However, inherent small-scale soil heterogeneities and nonlinearity of processes dominate spatial and temporal variability of soil moisture and introduce sources of error that can produce significant misinterpretation of hydrological scenarios and unrealistic predictions. At the basin scale (2500 $25000 \mathrm{~km}^{2}$ ), remote sensing technology, both active and passive, has demonstrated the potential to map and monitor surface soil moisture changes over large areas at regular intervals in time (Barrett et al., 2009). Satellites with L-band radiometers, e.g. SMOS (Kerr et al., 2001), and the planned SMAP mission (Entekhabi et al., 2010), or gravity change detection, GRACE (Tapley et al., 2004), provide a spaceborne Earth observation with opportunities to estimate soil water content at continental scale.

Although these techniques are promising, current measurement capabilities still do not cover the crucial need of hydrological observations corresponding to soil moisture in the root zone at the scale of a field, a small watershed scale

Published by Copernicus Publications on behalf of the European Geosciences Union. 
or a hydrologic response unit. New measurement methodologies of soil moisture are investigated to obtain more information on this intermediate scale, e.g. spatial TDR soil moisture measurements (Graeff et al., 2010), ground penetrating radar (GPR) measurements (Huisman et al., 2003), electrical resistivity tomography (ERT) measurements (Garre et al., 2011), or ground-based microwave radiometry (Schwank et al., 2009). In practice, these techniques are limited to the estimation of soil moisture at the very surface, influenced by soil chemistry, hindered by vegetation cover, and limited in temporal or spatial coverage. In general, there are either invasive methods that can detect also deeper soil moisture, but in a point-like manner, or non-invasive or remote sensing methods with high spatial coverage but representing shallow soil only. Ground penetrating radar can do a deeper assessment non-invasively, but it is costly and only an indirect measurement.

Recently two novel methods were introduced that potentially can fill the gap of soil moisture measurements at the field scale: (i) the cosmic-ray neutron sensing method (Zreda et al., 2008), preferably called ground albedo neutron sensing (GANS), and (ii) measuring water storage changes by a high-precision gravimeter (Creutzfeldt et al., 2010). While both are non-invasive and detect water storage changes in a similar integration area, called footprint or support scale, the gravimeter is less mobile and its measurement includes also water stored in shallow groundwater (Christiansen et al., 2011; Leirião et al., 2009); and thus an estimation of soil moisture itself is more complicated. We will focus here on the ground albedo neutron sensing method, which counts background neutrons generated in land surface materials by secondary cosmic rays, following a terminology according to Kodama (1980) and Kodama et al. (1985) instead of the name “cosmic-ray (neutron) sensing" used by Zreda et al. (2008).

In earlier studies, Kodama (1984) described the possible applications of measuring cosmic radiation for estimations of snow water equivalent and also soil moisture by belowground measurements (Kodama et al., 1985). At the laboratory scale, Oswald et al. (2008) and Tumlinson et al. (2008) presented an imaging technique (2-D and 3-D) based on a beam of low energy neutrons to investigate water redistribution and plant water uptake of a single plant in detail. Recently, using neutron transport simulations and field measurements, Zreda et al. (2008) and Desilets et al. (2010) introduced a new methodology of soil moisture measurements via counting natural aboveground fast neutrons, generated primarily by interactions of secondary cosmic-ray neutrons with terrestrial and atmospheric nuclei. These neutron intensities are inversely correlated with soil moisture over an integration area, called footprint, with diameter of ca. $600 \mathrm{~m}$ (at sea level). The penetration depth of the measurement of ground albedo neutrons, taken as the depth up to which $86 \%$ (i.e. all but two $e$-folds) of the counted neutrons originate, ranges up to few decimetres. The method is based on the crucial role of hydrogen as neutron moderator due to its scattering cross-section of ca. 20 barns (Horsley, 1966) compared to others elements present in parents rocks (e.g. 2.167 barns for Si, see Table 1) (Sears, 1992).

Neutrons at the air/ground interface are moderated by any chemical and physical form of hydrogen ${ }^{1} \mathrm{H}$ in or above soil surface, e.g. soil moisture, snow, intercepted water, biomass, and carbohydrates. Therefore, there is still an open question if the non-invasive ground albedo neutron sensing method is suitable to quantify water stored in different reservoirs at the field scale.

In this manuscript, we present a study of aboveground albedo neutrons for the estimation of soil moisture at an agricultural site in northern Germany. We quantified the relative influence of crop biomass during summer and investigated the impact of snow during winter. This study has been designed to

- extend the first applications of the GANS methodology, there called cosmic-ray (neutron) sensing, to a different geographical context,

- monitor ground albedo neutrons under two different vegetative situations (cropped field and bare soil) and different seasonal conditions (summer and winter),

- measure temporal variability of soil moisture at the ground/air interface and to evaluate the effective response of the ground albedo neutron method to hydrological events.

\section{Materials and methods}

\subsection{Basis of the GANS method to detect soil moisture}

Primary cosmic rays that hit the Earth consist mostly of charged protons. Partly these primary cosmic rays are deflected before the top atmosphere by Earth's magnetic field. Because of the spatial variability of Earth's magnetic field, e.g. with latitude, the intensity of high-energy cosmic rays varies in space. The incoming cosmic-ray intensity also varies with the solar activity (Parker, 1965). However, this variability will be neglected here because it is mainly a longer term modulation and is usually of the order of $1 \%$ or less in amplitude (Kodama et al., 1985).

In the atmosphere, incoming protons generate a cascade of secondary cosmic rays as product of their collision with atmospheric nuclei (Lal and Peters, 1967). The intensity of this secondary cascade is related to how much air mass was encountered during the transit through the overlying atmosphere. Therefore, variations of air pressure affect the intensity of secondary cosmic ray fluxes at the near-surface atmosphere.

Once the secondary cascades of cosmic rays arrive at the ground level, these collide with the land surface, where lower 
Table 1. Nuclear properties of major rock constituents: atomic number $(Z)$, atomic weight $(A)$ in grams, total scattering cross section $\left(\sigma_{\mathrm{S}}\right)$, absorption cross section $\left(\sigma_{a}\right)$ for $2200 \mathrm{~m} \mathrm{~s}^{-1}$ neutrons $\left(20^{\circ} \mathrm{C}\right)$, average number of collisions (NC) required to reduce a neutron's energy from $2 \mathrm{MeV}$ to $0.025 \mathrm{eV}$ by elastic scattering, average logarithmic energy decrement per collision $(\xi)$, and neutron stopping power (SP). Cross sections units in barn $\left(1\right.$ barn $\left.=10^{-24} \mathrm{~cm}^{2}\right)$ and values were extracted from Sears (1992). Calculations are based on equations presented in Rinard et al. (2009) and Krane (1988)*.

\begin{tabular}{llllllcl}
\hline Element & $Z$ & \multicolumn{1}{c}{$A$} & \multicolumn{1}{c}{$\sigma_{\mathrm{S}}$} & \multicolumn{1}{c}{$\sigma_{a}$} & $\mathrm{NC}$ & \multicolumn{1}{c}{$\xi$} & \multicolumn{1}{c}{$\mathrm{SP}$} \\
\hline $\mathrm{H}$ & 1 & 1.00794 & $22.02^{* *}$ & 0.3326 & 26 & 1.000 & 22.020 \\
$\mathrm{~B}$ & 5 & 10.811 & 5.24 & 767 & 108 & 0.174 & 0.913 \\
$\mathrm{C}$ & 6 & 12.0107 & 5.551 & 0.0035 & 119 & 0.158 & 0.876 \\
$\mathrm{~N}$ & 7 & 14.0067 & 11.51 & 1.9 & 137 & 0.136 & 1.569 \\
$\mathrm{O}$ & 8 & 15.9994 & 4.232 & 0.00019 & 155 & 0.120 & 0.508 \\
$\mathrm{Na}$ & 11 & 22.98987 & 3.28 & 0.53 & 219 & 0.085 & 0.277 \\
$\mathrm{Mg}$ & 12 & 24.305 & 3.71 & 0.063 & 230 & 0.080 & 0.297 \\
$\mathrm{Al}$ & 13 & 26.98154 & 1.503 & 0.231 & 255 & 0.072 & 0.109 \\
$\mathrm{Si}$ & 14 & 28.0855 & 2.167 & 0.171 & 265 & 0.070 & 0.151 \\
$\mathrm{Cl}$ & 17 & 35.453 & 16.8 & 33.5 & 332 & 0.055 & 0.930 \\
$\mathrm{~K}$ & 19 & 39.0983 & 1.96 & 2.1 & 365 & 0.050 & 0.099 \\
$\mathrm{Ca}$ & 20 & 40.078 & 2.83 & 0.43 & 374 & 0.049 & 0.139 \\
$\mathrm{Mn}$ & 25 & 54.938 & 2.15 & 13.3 & 509 & 0.036 & 0.077 \\
$\mathrm{Fe}$ & 26 & 55.845 & 11.62 & 2.56 & 517 & 0.035 & 0.411 \\
$\mathrm{Ag}$ & 47 & 107.8682 & 4.99 & 63.3 & 991 & 0.018 & 0.092 \\
\hline
\end{tabular}

* Information for other materials is presented in the auxiliary material mentioned in Zreda et al. (2008) and available at: ftp://ftp.agu.org/apend/gl/2008gl035655/.

** See Horsley (1966) for values in different energies.

energy neutrons are created as product of these new interactions between secondary cosmic rays and land surface materials (soil, snow, plant canopies, etc.). Cosmic-ray neutrons in the intermediate energy level (1-2 MeV), fast neutrons (Hess et al., 1961), penetrate the soil. They are scattered and randomly distributed below- and above-ground losing kinetic energy in the course of several successive collisions with nuclei in the soil, land surface cover and near-surface atmosphere, while some are absorbed at some stage.

Hydrogen plays an important role on the moderation of neutrons. For example, a fast neutron requires only 26 collisions with hydrogen nuclei to decrease its energy from $2 \mathrm{MeV}$ (fast level) to $0.025 \mathrm{eV}$ (thermal level), compared to other common elements such as C (119 collisions), O (155 collisions), N (137 collisions), Al (255 collisions), Si (265 collisions), etc. (Table 1). In conclusion, hydrogen in water molecules is the key factor to moderate these neutrons and thus the intensity of neutrons above the ground surface strongly depends on the water mass present in soil. This allows a non-invasive indirect measurement of soil moisture.

\subsection{Quantitative soil moisture estimation by ground albedo neutron measurements}

Ground albedo neutrons can be detected by special counters. They count events resulting from neutrons passing the detector during a preset integration period. Based on neutron transport modeling studies an equation was derived by Desilets et al. (2010, Appendix A, A1) that could be used to relate albedo neutron flux and soil moisture, as follows below. However, we specify here also the approach to normalize and correct the neutron counting rates, with the aim to ease the practical application of the method.

$\theta=\left[\frac{a_{o}}{\left(N_{R}-a_{1}\right)}-a_{2}\right] \cdot \rho_{\mathrm{b}} / \rho_{\mathrm{wat}}$

where $\theta$ is the volumetric areal mean soil moisture $\left[\mathrm{m}^{3} \mathrm{~m}^{-3}\right]$, $N_{R}$ is the normalized and pressure-corrected neutron counting rate [-] (specified in Eq. 3), $\rho_{\mathrm{b}}$ is the mean bulk density $\left[\mathrm{kg} \mathrm{m}^{-3}\right], \rho_{\text {wat }}$ is water density $\left[\mathrm{kg} \mathrm{m}^{-3}\right]$, and $a_{i}$ are fitting parameters [-].

The intensity of secondary cosmic rays reaching the land surface fluctuates with changes in the mass density of the atmosphere, i.e. actually atmospheric pressure. Thus, neutron counting rates can be corrected by accounting for fluctuations of atmospheric pressure as follows (e.g. Bachelet et al., 1965):

$N=N_{\text {raw }} \cdot \exp \left[\beta\left(P-P_{\text {mean }}\right)\right]$

where $N_{\text {raw }}$ is the value of ground albedo neutrons observed in a moderated counter and measured in a fixed time period, $\beta$ is the atmospheric attenuation coefficient for ground albedo neutrons $\left[\mathrm{mbar}^{-1}\right], P$ is the local pressure corresponding to the period when $N_{\text {raw }}$ was observed and $P_{\text {mean }}$ is the long-term mean local pressure [mbar].

The integration period of ground albedo neutrons depends on the desired accuracy of soil moisture measurements. Events of neutron counting rates follow a Poisson distribution, which suggests that the standard deviation of neutrons counted in a fixed interval is equal to the square root of the total counts. The accuracy also depends on both detection efficiency and effective volume of the detector (Kodama et al., 1985). The range of neutron counting rates depends on several variables (e.g. site altitude, fluctuation of incoming protons due to solar activity changes, and other types of moderation such as biomass or open water bodies nearby), where site altitude usually is the predominant one. Neutron counting rates are substantially lower in altitudes at sea level than at mountain altitudes; therefore, GANS measurements of soil moisture at lower altitudes require longer integration periods of neutron counts.

Based on Eq. (2), the normalized and pressure-corrected neutron counting rate $\left(N_{R}\right)$ is defined as

$$
\begin{aligned}
N_{R}= & \frac{N_{\text {raw }} \cdot \exp \left[\beta\left(P-P_{\text {mean }}\right)\right]}{N_{\text {dry_raw }} \cdot \exp \left[\beta\left(P_{\text {dry }}-P_{\text {mean }}\right)\right]}= \\
& \frac{N_{\text {raw }}}{N_{\text {dry_raw }}} \cdot \exp \left[\beta\left(P-P_{\text {dry }}\right)\right]
\end{aligned}
$$

where $N_{\text {dry_raw }}$ is the number of ground albedo neutrons observed in a moderated counter and measured under dry soil conditions and $P_{\text {dry }}$ is the local pressure corresponding to the 
dry condition when $N_{\text {dry_raw }}$ was observed. The attenuation coefficient $(\beta)$ for neutron fluctuations induced by local air pressure was calculated from historical data of ground albedo neutrons and air pressure from the most proximal station of the worldwide network of standardized neutron monitors in Kiel, Germany, located at $54.34^{\circ} \mathrm{N}, 10.12^{\circ} \mathrm{E}$ and $54 \mathrm{~m}$ a.s.l. (see more below).

The dry condition state chosen to normalize the neutron counting rates have an influence on the parameter values in Eq. (1). It can be shown, that using a different dry condition state and accordingly a different neutron count rate $\left(N_{\text {dry_raw }}^{\prime}=\alpha N_{\text {dry_raw }} ; P_{\text {dry }}^{\prime}=\gamma P_{\text {dry }}\right)$ leads to a conversion of parameters $a_{0}$ and $a_{1}$, i.e. they have only to be divided by a constant factor $\alpha \cdot e^{\beta \cdot P_{\mathrm{dry}} \cdot(\gamma-1)}$, leaving the calibration curve Eq. (1) otherwise unchanged (see Appendix). This implies that using a different dry condition state for normalization, e.g. a drier state observed later, will not change the derived values of soil moisture $\theta$, if converted values of $a_{0}$ and $a_{1}$ are used in the equation.

The second type of corrections of neutron counting rates in the air/ground interface is due to variations of high energy primary cosmic rays. Existing databases of neutron monitoring worldwide stations observe spatial variations and temporal fluctuations of incoming cosmic rays. The four most proximal stations KIEL (Kiel, Germany), LMKS (Lomnicky stit, Slovakia), JUNG (Jungfraujoch, Switzerland) and ROME (Rome, Italy) were selected to obtain hourly changes of neutron counting rates exclusively due to fluctuations of incoming high energy cosmic rays. Time series of hourly ground albedo neutron counts were normalized to the maximum value observed in each station during the selected period. Normalized neutron fluxes in all these stations were quite similar despite different detection sensitivities, e.g. different neutron detectors (18-NM64 in KIEL, 8-SNM15 in LMKS, 18-IGY in JUNG and 20-NM64 in ROME). Our analysis showed that incoming cosmic rays did not substantially vary during our observation period. For example, mean value and standard deviation were 174.3 and 1.5 counts per second at KIEL station, respectively. This standard deviation is far less than the variability, between maximum and minimum periods of solar activity, of 40 counts per second, reported from this station during the last decades. Therefore, we assumed that a correction of neutron counting rates for the variations of incoming primary cosmic rays is not necessary, at least for our observations.

\subsection{Horizontal and vertical coverage of the GANS method}

Horizontal spatial coverage of the cosmic-ray neutron sensing method or GANS method can be defined as the region within which $86 \%$ of the counted albedo neutrons are originated (Zreda et al., 2008). Since ground albedo neutrons depend on atmospheric pressure, also the footprint is inversely proportional to atmospheric pressure. Probability of neutron collisions with nuclei in air is significantly less than in soil because of its lower water content (specifically $\mathrm{H}$ ) compared to soil. This probability is expressed on the basis of length (macroscopic cross-section, $\Sigma=N \sigma\left[\mathrm{m}^{-1}\right]$ ) and is a function of the atom density $(N)$ and energy-dependent element crosssection $(\sigma)$. Therefore, the neutron counting rate above the ground surface is a measure of intensity in soil (Shuttleworth et al., 2010). By means of simulations, Zreda et al. (2008) suggested to adopt a $600 \mathrm{~m}$ diameter footprint at sea level, rather independent of soil moisture level.

The depth of measurement of the GANS method depends mostly on soil moisture, because the probability of neutron scattering and absorption events depends on the number of hydrogen molecules. Hydrogen has a higher scattering crosssection compared to common elements in rocks. Numerical simulations by the Monte Carlo Neutron Particle (MCNP) transport code (Briesmeister, 1997) suggest in silica matrix a vertical coverage by albedo neutrons counted aboveground ranging from about $0.8 \mathrm{~m}$ in dry soils to $0.1 \mathrm{~m}$ in wet soils (Zreda et al., 2008). A very descriptive feature of the transmission of ground albedo neutrons produced by secondary cosmic rays through the soil porous media is the mean-free path length, $\overline{\lambda_{\mathrm{m}}}[\mathrm{m}]$, given as follows:

$\overline{\lambda_{\mathrm{m}}}=\frac{1}{\Sigma_{\mathrm{t}}}=\frac{1}{\theta(\Sigma)_{\text {water }}+(1-n)(\Sigma)_{\text {soil }}+(n-\theta)(\Sigma)_{\text {air }}}$

where $\Sigma_{\mathrm{t}}$ is the total material cross-section $\left[\mathrm{m}^{-1}\right], \theta$ is volumetric soil moisture $\left[\mathrm{m}^{3} \mathrm{~m}^{-3}\right], n$ is soil porosity [-], and $\Sigma_{i}$ is the macroscopic cross-section of material $i$ (water, soil or air) as described above $\left[\mathrm{m}^{-1}\right]$. Equation (5) is derived from Eqs. (12-8) in Rinard et al. (2009) assuming a volumetric mixture of water, soil and air in the porous media. The meanfree path length is an indicator of the soil depth from which ground albedo neutrons can be detected assuming homogeneous soil chemical characteristics under variable-saturation conditions (neutron moderation by air in void volume). It depends not only on the type of material but also on the energy of the neutron penetrating the medium, because their total macroscopic cross-section changes with neutron energy (Horsley, 1966).

However, if only ground albedo neutrons (from epithermal to fast level) are counted aboveground, the mean-free path length depends only weakly on the chemical composition of the soil, as shown by Zreda et al. (2008). Therefore, a count of ground albedo neutrons in this energy range will predominantly depend on soil moisture. And worth mentioning, the neutrons detected in the sensor come from a broad range of angles, including almost horizontal ones. However, this deflected angle after collision does not strongly affect the counting probability, because mean-free path length in air is typically in the order of tens of meters. This is also the reason why the height of a neutron counter above ground surface is not sensitively influencing counting rates as long as it is not shielded by surface structures and is lower than the mean-free path length in air. 


\subsection{Experimental site}

The non-invasive GANS method for estimation of soil moisture was tested in a 30 ha agricultural field in Bornim (Brandenburg, Germany). The test site is located close to Potsdam, and $30 \mathrm{~km}$ west of Berlin (Fig. 1). The landscape at the site was formed during the last ice age. Soil consists in the upper one meter of $75 \%$ sand, $17.2 \%$ silt and $7.8 \%$ clay (Gebbers et al., 2009). Texture analysis was done for a number of nearsurface samples, and a loamy sand type is predominant in all 19 selected sampling locations (Fig. 1). Percentages of sand (between 77.8 and $86.2 \%$ ), silt (between 8 and $14.8 \%$ ) and clay (between 4.8 and $9.4 \%$ ) always indicated this soil classification, in agreement with the previous work in the area nearby (Gebbers et al., 2009).

The period of highest precipitation in Potsdam usually is between May and August, but varying between the years. Total annual precipitation ranged between $374.6 \mathrm{~mm}$ (1976) and $825.9 \mathrm{~mm}$ (2007), based on the long term meteorological record of the period 1893-2010 (Meteorological Station Potsdam Telegrafenberg - Germany). Averaged in this period, the mean monthly relative humidity seasonally varies between $67.6 \%$ (May) and $89.3 \%$ (December). Analogously, the monthly averaged daily mean air temperature were recorded as $-1{ }^{\circ} \mathrm{C}$ (January) to $18^{\circ} \mathrm{C}$ (July) in this period.

The monitoring period started on 27 August 2010 when the field was cropped with corn (Zea Mays). The monitoring continued until corn was harvested on 14 September 2010. A second monitoring period started on 26 November 2010 in a condition of bare soil and continued until the end of March 2011. Thus, the first period covered a part of late summer and the second period covered the transition from late autumn to the beginning of spring. Weather data was provided from the nearby station of Leibniz Institute for Agricultural Engineering Potsdam-Bornim (ATB) located about $1 \mathrm{~km}$ from the field site. Snow fall data were taken from the Meteorological Station Potsdam Telegrafenberg located about $6 \mathrm{~km}$ to the east.

\subsection{Biomass and the GANS method}

The role of biomass on estimations of soil moisture by means of the GANS method is still under debate. The presence aboveground biomass could affect the ground albedo neutrons in two ways: (1) the biomass produces moderating effects on incoming cosmic rays and on ground albedo neutrons before they reach the detector, mainly by its water content, and (2) scattering and absorption properties of other biomass constituents (e.g. carbohydrates) also reduce neutron fluxes at the ground/air interface. It can be expected that vegetation with lower biomass will have a less important influence on incoming cosmic rays and albedo neutrons emanating from soil.
In order to understand the influence of biomass on the GANS method, spatial and temporal variability of corn was monitored. Two field campaigns (19 August 2010 and 6 September 2010) were performed to measure the crop height for a total of 96 points according to the sampling grid shown in Fig. 1. Moreover four areas of $1 \mathrm{~m}^{2}$ with four different mean crop heights, covering the full range of heights observed previously were selected for biomass measurements. Biomass samples were subsequently dried in the oven. Crop height, wet biomass and dry biomass measurements were used to establish an empirical relationship between biomass water in corn and crop height.

\subsection{Ground Albedo Neutron Sensing (GANS)}

At the experimental field site, two "types" of cosmic-ray neutron sensors (CRS-1000, Hydroinnova, Albuquerque, USA) were installed. These devices only recently became available commercially. One probe contained two proportional counters, one counter surrounded by a low-density polyethylene and a second, bare counter (Fig. 2a). The second CRS1000 had a moderated proportional counter only. Moderated counters monitor epithermal to fast neutrons, whereas the bare counter measures neutrons predominantly in the thermal energy range. All these neutron detectors applied at the field site are proportional counters filled with He-3 gas ( $2 \mathrm{~atm}$ pressure). Neutron detector tubes interface directly to a Neutron Pulse Module, NPM, (Q-NPM-2000-HV, Quaestra Instruments LLC, Tucson, AZ) with integrated 2000V high voltage supply and Multi-Channel Analyzer (MCA).

The sensors were mounted on a pole in the middle of the field $\left(52.431^{\circ} \mathrm{N}, 13.021^{\circ} \mathrm{E}\right.$, WGS84, $84 \mathrm{~m}$ a.s.l.) at a height of $1.5 \mathrm{~m}$ aboveground surface in order to collect ground albedo neutrons from a footprint (Fig. 1), ca. $600 \mathrm{~m}$ diameter, as specified by Desilets et al. (2010). The two CRS-1000 were placed $6 \mathrm{~m}$ apart, thus purposely with a large overlap in their footprint (Fig. 2b). Neutron pulse counting modules of the CRS-1000 were set-up to record counts every $20 \mathrm{~min}$; in data processing, neutron counts were integrated in one-hour time intervals.

\subsection{Soil moisture network and field campaigns}

In parallel to measurements of ground albedo neutrons, soil moisture data at point-scale was monitored by using classical techniques. A soil moisture network consisting of 16 Theta probes MR2 (Delta-T Devices Ltd., Cambridge, UK) with data loggers was installed at the experimental site. The probes measure the soil moisture based on the Frequency Domain Reflectometry (FDR) approach. Sampling design in the first monitoring period used $16 \mathrm{MR} 2 \mathrm{~s}$ on the surface level spaced as shown in Fig. 1. Some of the MR2s were damaged during this period by animals or intruding water. The second monitoring period used only five locations in the experimental field: point 8 (center), point 9 (north), point 7 (south), 


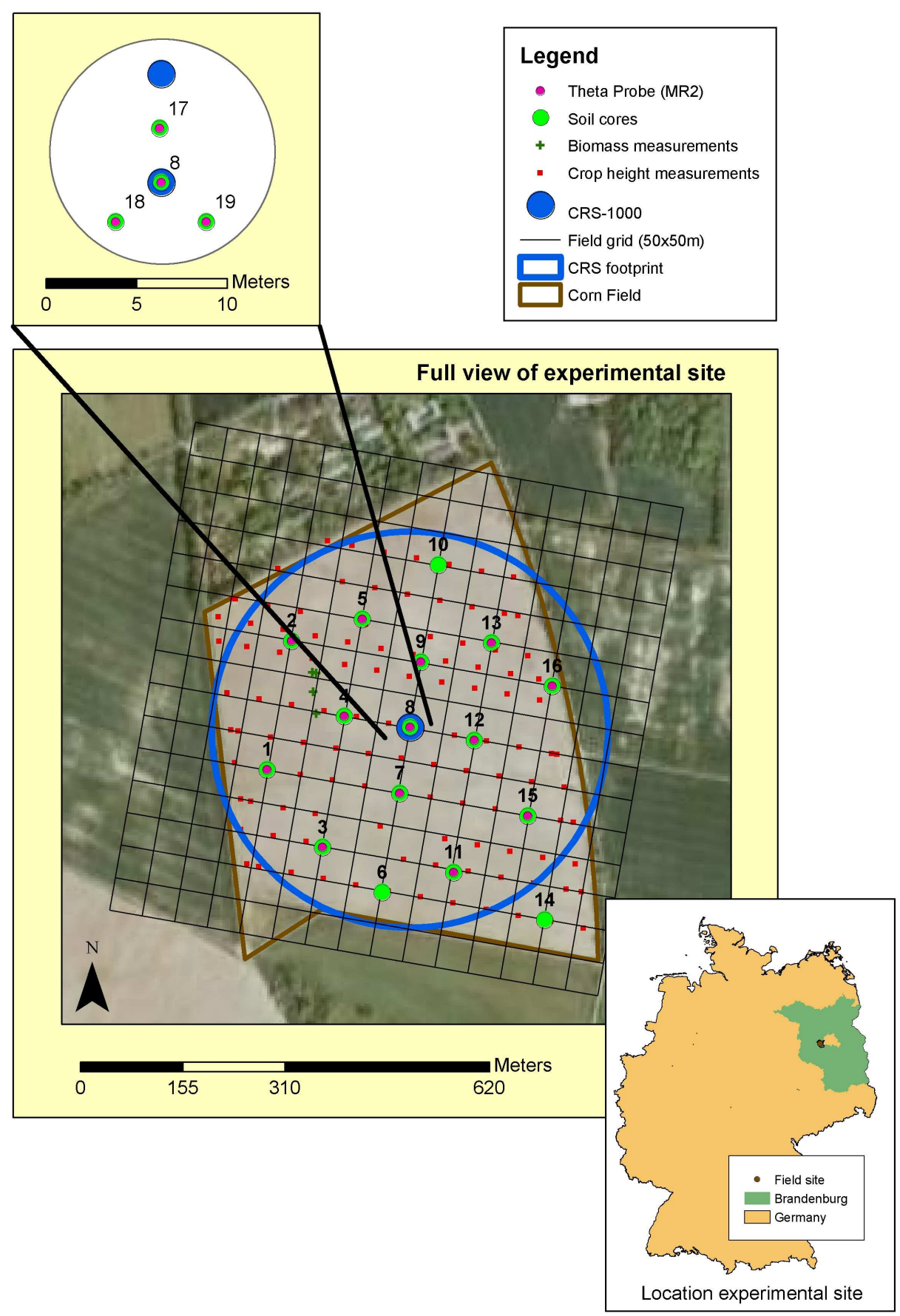

Fig. 1. Location of experimental site and its hydrological instrumentation.

point 4 (west) and point 12 (east) as shown in Fig. 1. Each location in the second period had three different depths for MR2 probes (surface representing $5 \mathrm{~cm}, 20 \mathrm{~cm}$ and $40 \mathrm{~cm}$ ).

Calibration of classical soil moisture devices was carried out collecting undisturbed soil samples during the different seasons (Table 2). Soil samples, $100 \mathrm{~cm}^{3}$ soil cores (UGT, Muencheberg, Germany), were used for gravimetrical estimation of soil moisture and bulk density. Also, soil texture was measured by means of the hydrometer method (Beverwijk, 1967), and classified by the United Stated Department of Agriculture (USDA) classification.

\subsection{Calibration of CRS-1000}

In literature, the calibration technique for CRS-1000 is only done by modeling neutron transport. Zreda et al. (2008) 


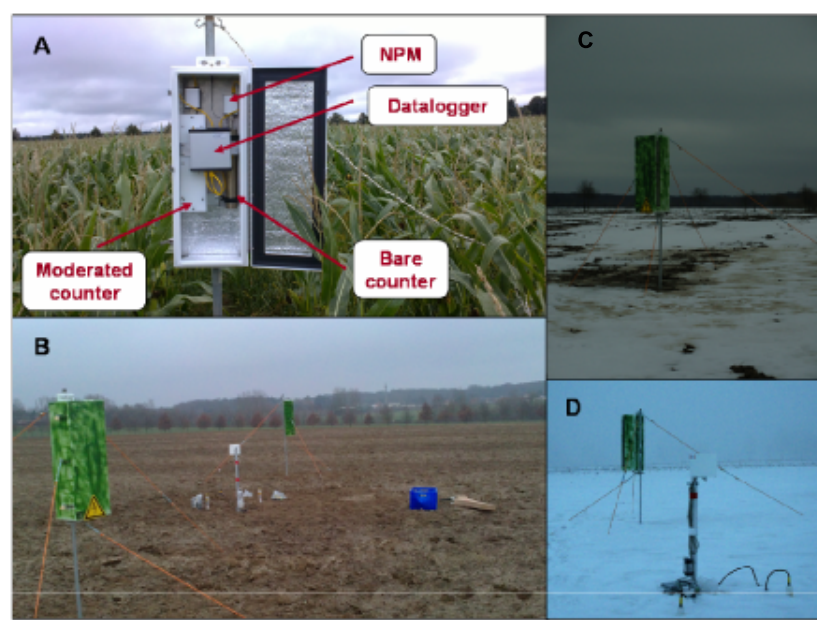

Fig. 2. Ground albedo neutron sensors (CRS-1000) under different field conditions in Bornim: (a) two-counters CRS-1000 and its parts in cropped corn field, (b) picture of two CRS-1000s in bare field condition, (c) picture of CRS-1000 at the beginning of snow cover condition, and (d) picture of CRS-1000, rain gauge and Theta Probes (MR2) during a day with maximum snow cover.

Table 2. Description of soil sampling campaigns at experimental site.

\begin{tabular}{cccrrr}
\hline Campaign & $\begin{array}{c}\text { Date } \\
{[\mathrm{dd} / \mathrm{mm} / \mathrm{yy}]}\end{array}$ & Season & $\begin{array}{c}\text { No. of } \\
\text { samples }\end{array}$ & $\begin{array}{c}\text { Mean soil } \\
\text { moisture } \\
{\left[\mathrm{m}^{3} \mathrm{~m}^{-3}\right]}\end{array}$ & $\begin{array}{c}\text { Standard } \\
\text { deviation } \\
{\left[\mathrm{m}^{3} \mathrm{~m}^{-3}\right]}\end{array}$ \\
\hline 1 & $03 / 08 / 10$ & Summer & 18 & 0.169 & 0.028 \\
2 & $11 / 08 / 10$ & Summer & 18 & 0.066 & 0.015 \\
3 & $16 / 08 / 10$ & Summer & 19 & 0.198 & 0.029 \\
4 & $06 / 09 / 10$ & Summer & 19 & 0.132 & 0.052 \\
5 & $11 / 02 / 11$ & Winter & 5 & 0.238 & 0.014 \\
\hline
\end{tabular}

and Desilets et al. (2010) evaluated the fitting parameters of Eq. (1) by means of simulating the relative neutron flux for a given volumetric soil moisture under simplified conditions in via the code Monte Carlo N-Particle Extended (MCNPX). Subsequently, an equation such as Eq. (1) was adjusted to match field soil moisture values (two points in time) by translating the curve until a least-squares fit was achieved. This calibration approach requires neutron modeling. Furthermore, these simulations currently are restricted to simple geometries.

To overcome these limitations we suggest a modified procedure to ease the practical application of the methodology without the need of modeling neutron scattering, and requesting intensive, but viable monitoring activities. In the particular approach implemented in this study we performed a calibration of CRS-1000 devices based on continuous data from a classical soil moisture network (see Sect. 2.7). Firstly, ground albedo neutron counting rates measured in the moderated counter $\left(N_{\text {raw }}\right)$ were normalized to a counting rate observed during dry conditions ( $\left.N_{\text {dry_raw }}\right)$. This neutron counting rate under dry conditions was taken from a period when lowest soil moisture values were measured in the MR2s. Classical soil moisture data here was only used to identify the drier period, but these data were not applied in the calibration procedure itself.

An important point of this calibration is that the penetration depth of the GANS method is variable depending on mean soil moisture values in the footprint. On the other hand, this penetration is relatively well known for wet conditions, and then the penetration depth, or vertical footprint, is about $10 \mathrm{~cm}$. Because of this, our calibration approach used spatially averaged surface soil moisture values from MR2s at 16 locations inside the footprint (Fig. 1), taken during periods when vertical penetration depth of CRS-1000 is comparable to the vertical coverage of surface MR2 devices. With this dataset a good calibration was achieved, as described in the following sections. However, an assessment of the actual vertical coverage of a CRS-1000 is an important topic that needs to be investigated further.

Since Eq. (1) presents three unknown fitting parameters, three short periods of soil moisture data were selected from the first monitoring period in order to calibrate the CRS1000 devices. These periods are chosen to cover a range of medium moist and the close-to-saturation conditions. A single set of calibration parameters using these periods was estimated by minimizing the root mean square error (RMSE) between MR2 and CRS-1000 data defined as follows:

$\mathrm{RMSE}=\sqrt{\frac{\sum_{i=1}^{i=n_{\mathrm{p}}}\left(\theta_{\mathrm{GANS}, i}-\theta_{\mathrm{MR} 2, i}\right)^{2}}{n_{\mathrm{p}}}}$

where $\theta_{\mathrm{GANS}, i}$ is the areal mean soil moisture inferred via the GANS method $\left[\mathrm{m}^{3} \mathrm{~m}^{-3}\right], \theta_{\mathrm{MR} 2, i}$ is the hourly value of soil moisture (mean value from 16 locations) $\left[\mathrm{m}^{3} \mathrm{~m}^{-3}\right]$, each at data point $i$ of a time series, and $n_{\mathrm{p}}$ is the number of data points considered in the calibration data. Subsequently, the soil moisture determined using the set of calibrated parameters was applied for the whole summer observation period and another period after harvest in winter.

The datasets used to estimate RMSE included hourly soil moisture data. Soil moistures values derived by GANS in Eq. (5) were estimated by using six-hours moving average of neutron counting rates. Either a moving average or longer integration periods of neutron data is required to achieve the desired accuracy of soil moisture measurements, because at a low altitude site such as Bornim, counting rates are notably smaller than at higher altitudes, e.g. previous studies of Zreda et al. (2008) and Desilets et al. (2010). 


\section{Results and discussion}

\subsection{Ground albedo neutrons under different field conditions}

Different scenarios observed at the field site showed a first opportunity to distinguish the influence of different sources of water (biomass water, soil moisture and snow pack) on the ground albedo neutron flux. In Table 3, we summarize ranges of neutron counting rates observed for three types of field conditions. Although, periods when the field was cropped or bare did not show significant difference in neutron counting rates, we found it useful to plot counting rates of ground albedo neutrons in different energy levels. Here, we introduce the Field Neutron Ratio $\left(N_{\mathrm{f}}\right)$ that could be an useful information to identify different field conditions from ground albedo neutron data alone, and probably also water in different environmental reservoirs, as follows:

$N_{\mathrm{f}}=\frac{C_{\mathrm{B}}}{C_{\mathrm{M}}-C_{\mathrm{B}}}$

where $C_{\mathrm{B}}$ and $C_{\mathrm{M}}$ are the ground albedo neutron counts per hour observed in the bare and in the moderated counter, respectively. Evaluation of $N_{\mathrm{f}}$ values for cropped field, for bare soil and for snow cover is shown in Fig. 3. This plot presents slightly different properties than usual in neutron physics, since CRS-1000 devices do not give exact energy information about neutrons recorded in the detector. This is the reason why we defined $N_{\mathrm{f}}$ using rates recorded in "bare" and "moderated" counters, which is more practicable. A similar approach was presented in the so-called "Cd-difference" by Kodama et al. (1985).

The ratio $N_{\mathrm{f}}$ ranged between 1.21 and 2.38 for croppedfield and between 1.24 and 2.34 for bare-field conditions. In both scenarios, $N_{\mathrm{f}}$ follows well a similar power law relation. Though $N_{\mathrm{f}}$ is slightly higher for cropped than bare field, the result overall corroborated that there was no significant difference between bare and cropped conditions.

One important issue in the ongoing-development of the GANS method is to quantify the influence of biomass. Therefore, direct measurements of plant biomass were carried out in this study. We determined an empirical relationship between wet and dry corn biomass per $\mathrm{m}^{2}$ and mean corn height $\left(r^{2}=0.98\right.$, data not shown). Biomass water and dry biomass in the CRS-1000 footprint were evaluated by measuring crop height at a number of locations. Two field campaigns (cf. Sect. 2.5) showed that height of corn (Zea Mays) strongly varied, showing values between 50 and $190 \mathrm{~cm}$ with a mean of $143 \mathrm{~cm}$. These campaigns took place only a few weeks before harvest. Thus, the biomass and especially biomass water may have not increased further, or even declined, because maize tends to dry at the end of summer. Very sandy locations showed reduced crop height. In the center and east, for example, soil had a higher silt and clay content and supported better crop growth. Assuming

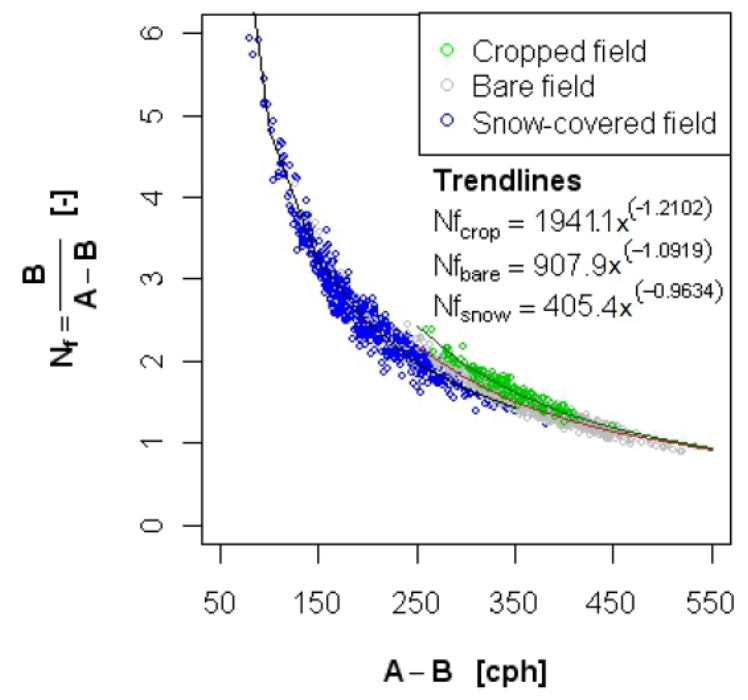

Fig. 3. Neutron counts in different field conditions. In the vertical axis, $N_{\mathrm{f}}$ is a field neutron ratio, here defined as ratio of bare counts per hour (B) over difference of moderated counts per hour (A) and bare counts per hour (B). In the horizontal axis, difference of moderated counts minus bare counts per hour.

the maximum crop height for everywhere in the footprint, biomass water was at most $100 \mathrm{Mg} \mathrm{ha}^{-1}$. In comparison to soil moisture, this estimation constitutes only $14.95 \%$ of the water mass for a $0.45 \mathrm{~m}$ soil column (mean CRS-1000 penetration) with mean soil moisture of $0.15 \mathrm{~m}^{3} \mathrm{~m}^{-3}$. This can be taken as a maximum estimate. We infer that a corn crop, in terms of biomass and biomass water, as a moderator of ground albedo neutrons, is of substantially less influence on neutron counting rates than soil moisture. This impact on neutron counting rates may be higher only for even drier conditions, e.g. $\theta<0.05 \mathrm{~m}^{3} \mathrm{~m}^{-3}$, or higher biomass cover than our maximum estimate for corn. However, these are quite unlikely conditions, more in combination, and therefore, we hypothesize that this assumption is true for cropped fields in general. This behavior can be expected to be different for other types of vegetation, especially forest.

During winter there was an early and relatively long period with a snow cover, starting on 2 December 2010 with $8 \mathrm{~cm}$. Snow water equivalent was measured as $19 \pm 3 \mathrm{~mm}$, $23 \pm 4 \mathrm{~mm}$ and $36 \pm 8 \mathrm{~mm}$ on 23 December 2010, 3 January 2011 and 7 January 2011, respectively based on four samples each day taken in the proximity of CRS-1000. Evaluating a five weeks period with continuous presence of snow cover (until 9 January 2011), neutron counting rates were slightly less than observed under bare field and cropped-field conditions (Table 3). Moreover, periods with and without snow cover could be distinguished by $N_{\mathrm{f}}$ (Fig. 3). Values of $N_{\mathrm{f}}$ were clearly shifted to larger values if a snow cover was present. Values of $N_{\mathrm{f}}$ between 1.24 and 5.93 corresponded to the snow-covered period. 
Table 3. Range of neutron counting rates observed in different field conditions.

\begin{tabular}{|c|c|c|c|c|c|c|c|}
\hline \multirow[t]{2}{*}{ Condition } & \multirow{2}{*}{$\begin{array}{c}\text { Period* } \\
{[\mathrm{dd} / \mathrm{mm} / \mathrm{yy}]}\end{array}$} & \multicolumn{3}{|c|}{$\begin{array}{l}\text { Moderated counter } \\
\text { [neutrons per hour] }\end{array}$} & \multicolumn{3}{|c|}{$\begin{array}{c}\text { Bare counter } \\
\text { [neutrons per hour] }\end{array}$} \\
\hline & & Range & Mean & St. Dev. & Range & Mean & St. Dev. \\
\hline Cropped soil & $27 / 08 / 10$ until $14 / 09 / 10$ & $790-1067$ & 918 & 52 & $500-659$ & 573 & 32 \\
\hline \multirow[t]{2}{*}{ Bare soil (without snow) } & $26 / 11 / 10$ until $01 / 12 / 10$ & $802-1045$ & 900 & 43 & $489-650$ & 557 & 30 \\
\hline & 10/01/11 until 25/03/11 & $687-1060$ & 838 & 79 & $398-649$ & 500 & 45 \\
\hline Bare soil (with snow cover) & 02/12/10 until 09/01/11 & $521-930$ & 730 & 85 & $387-621$ & 519 & 48 \\
\hline
\end{tabular}

* Short gaps due to battery failure.

Neutrons are slowed down and absorbed efficiently in water. Therefore, numbers of ground albedo neutrons detected aboveground are substantially different when a snow layer is present. This explains why neutron counting rates observed during winter differ between periods with or without a snow layer. Kodama et al. (1979) reported that the attenuation character of neutrons in snow cover is influenced by the so-called boundary effect of air-snow-soil layers. During the initial phase of snow accumulation $(\sim 30 \mathrm{~cm}$ water depth) there is a steep decrease of neutron counting rates due to air-water boundary low energy neutrons (as observed in a bare counter). But Kodama et al. (1979) observed also that this behavior disappeared when neutrons of higher energy (e.g. those observed in a moderated counter) were measured. Based on observations at our field site, we also can conclude that snow cover plays a substantial role on moderation of neutrons, and shifts counting rates to higher $N_{\mathrm{f}}$ values more strongly than both biomass and soil moisture (Fig. 3).

\subsection{Calibration for soil moisture estimations}

\subsubsection{Classical monitoring network}

Due to the relative homogeneous classification of the soil type in the field (cf. Sect. 2.4), the same calibration function for all MR2 probes could be used. A standard calibration function for mineral soil type provided by MR2 was tested against soil samples (Fig. 4). Gravimetric soil moisture was converted to volumetric soil moisture by multiplying bulk density estimated from undisturbed soil cores. The mean value of bulk density was $1.40 \mathrm{~g} \mathrm{~cm}^{-3}$ with a standard deviation of $0.12 \mathrm{~g} \mathrm{~cm}^{-3}$. Soil moisture estimated from undisturbed soil cores varied between 0.049 and $0.233 \mathrm{~m}^{3} \mathrm{~m}^{-3}$ with a mean value of $0.14 \mathrm{~m}^{3} \mathrm{~m}^{-3}$. The MR2 measurements gave values between 0.106 and $0.283 \mathrm{~m}^{3} \mathrm{~m}^{-3}$ with a mean value of $0.16 \mathrm{~m}^{3} \mathrm{~m}^{-3}$. The coefficient of correlation and RMSE between MR2 data and field measurements of soil moisture (soil cores) were 0.84 and $0.034 \mathrm{~m}^{3} \mathrm{~m}^{-3}$, respectively. A specific calibration for each MR2 could be evaluated for further research focused on the assessment of the spatial variability inside the footprint. However, considering

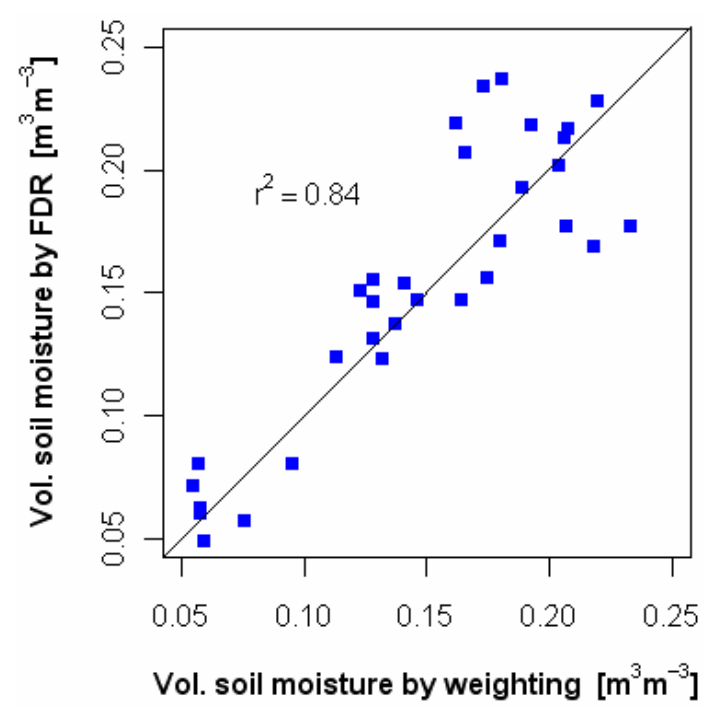

Fig. 4. Calibration of Theta Probes (MR2): observed soil moisture from soil cores and soil moisture measured by MR2s.

the aim of this study and the relatively few number of samples at each location, the standard calibration function for mineral soil type was considered to give a sufficient representation and thus was used for all MR2.

\subsubsection{Ground albedo neutron sensor CRS-1000}

Ground albedo neutrons observed in the two different probes had a similar response during the entire two monitoring periods. Neutrons monitored in the two moderated counters of the CRS-1000s showed a correlation coefficient of 0.81 for one-hour integration periods (Fig. 5a). For an integration period of six hours, and thus a lower statistical variability of counts, the correlation between the two moderated counters increased to 0.97 (data not shown). This demonstrates that the counters functioned in the same way and also that the distance of $6 \mathrm{~m}$ between probes did not lead to significant differences.

Neutron rates were indeed inversely correlated to local atmospheric pressure as expected (Fig. 5b). After local 

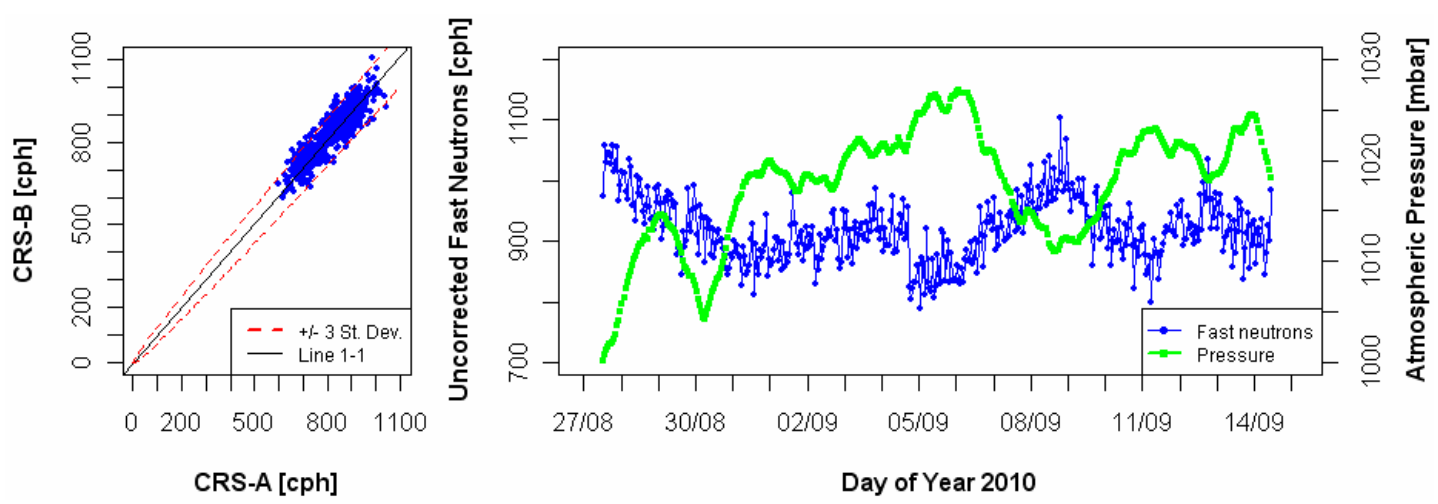

Fig. 5. Ground albedo neutrons in moderated counter under cropped field conditions: (left) correlation of ground albedo neutron counting rates per hour between two CRS-1000 sensors, and (right) temporal variability of uncorrected ground albedo neutron counting rates per hour and local atmospheric pressure.

correction of neutron counting rates due to fluctuations of atmospheric pressure (between 1000.10 and $1026.96 \mathrm{mbar}$ ), ground albedo neutrons ranged between 781 and 1103 counts per hour. The maximum value of ground albedo neutrons per hour (1067), which coincided with a period of no precipitation events and minimum soil moisture value, was used as $N_{\text {dry_raw }}$ for normalizing neutron counts of Eq. (3).

In order to relate neutron counting rates with soil moisture according to Eq. (1), three datasets representing soil moisture values shortly after rain events with maximum cumulative values (16.7, 8.2 and $4.9 \mathrm{~mm}$ ) were selected as calibration data. These soil moisture measurements come from three separate time periods of about a day only each, and are jointly used for a single fit of calibration parameters. They were chosen to cover a range of medium soil moisture values, but avoiding situations where the top part of the soil had dried out while the lower part may still be much moister. The latter is to ensure that the local soil moisture measurements represent a similar soil moisture state than the CRS-1000 signal. No weighting of the local soil moisture measurements was applied (cf. Eq. 5), though shallower and horizontally closer locations contribute more to the neutron counts in the CRS-1000 than deeper and more distant locations in the footprint. The spatial coverage in the vertical and horizontal will have to be investigated further to be able to define a suitable weighting scheme, with the aim to improve the calibration of a GANS probe and to better understand how neutron counts represent soil moisture in the footprint. It can be expected that such a weighting is required the less homogeneous the footprint is in respect to soil texture, vegetation type and aboveground biomass. At our cropped field the conditions were relatively homogeneous and thus a procedure without spatial weighting of local soil moisture data seems appropriate, opposed to, e.g. a forest site.

These datasets of $26 \mathrm{~h}$ (between 29 August 2010 13:00 LT and 30 August 2010 14:00 LT), 20h (between 4 September 2010 17:00 LT and 5 September 2010 12:00 LT) and
$14 \mathrm{~h}$ (between 13 September 2010 17:00 LT and 14 September 2010 06:00 LT) had soil moisture mean values of 0.261, 0.191 and $0.141 \mathrm{~m}^{3} \mathrm{~m}^{-3}$, respectively (Figs. 6a and 7). By calibration, a good fit between the soil moisture MR2 data and soil moisture measurements by the GANS method was obtained with values of $0.465,0.1125$ and 0.49 for the fitting parameters $a_{0}, a_{1}$ and $a_{2}$, respectively. These fitting parameters showed a small minimum RMSE of $0.019 \mathrm{~m}^{3} \mathrm{~m}^{-3}$. This value of RMSE is similar to the accuracy of CRS-1000 for a six-hour integration period (0.013), which can be inferred from the standard deviation of the mean neutron counting rate (5504 counts in six hours). The coefficient of correlation between CRS-1000 soil moisture measurements and the mean value of MR2 soil moisture observations was 0.98 (Fig. 6b).

The fitting parameters presented in this study were derived via the data from the three selected periods of the measured soil moisture time series. In these periods values of $N_{R}$ ranged between 0.784 and 0.906 . This normalization was based on the reference $N_{\text {dry_raw }}$ used to calculate $N_{R}$. This reference value to represent dry conditions was taken from another period, identified by soil moisture measurements in the field.

The applicability of the calibration function is not limited to the values occurring in the three selected periods used for the calibration, as an empirical calibration would be, because the form of our calibration function is based on the results from a statistical simulation of neutron transport, fully based on physical principles (Desilets et al., 2010; A1). Therefore, this equation should allow also evaluating soil moisture for a broad range of sensible soil moisture values. However, there is a mathematical limitation for $N_{R}$ when it approaches $a_{1}$, but this is not to be expected to occur, at least for our field site (cf. Fig. 6). However, the calibration function type, derived by Desilets et al. (2010), might depend on some sensor characteristics such as its geometry, He-3 gas pressure, moderator material surrounding the neutron counter, etc., since all 


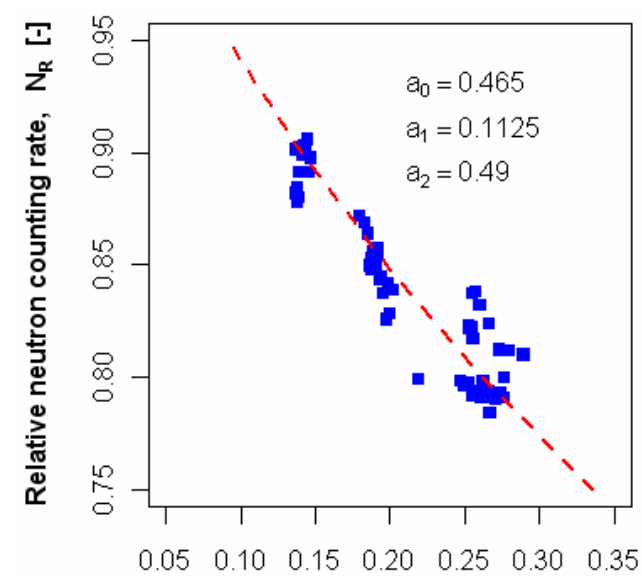

Vol. soil moisture by FDR $\left[\mathrm{m}^{3} \mathrm{~m}^{-3}\right]$

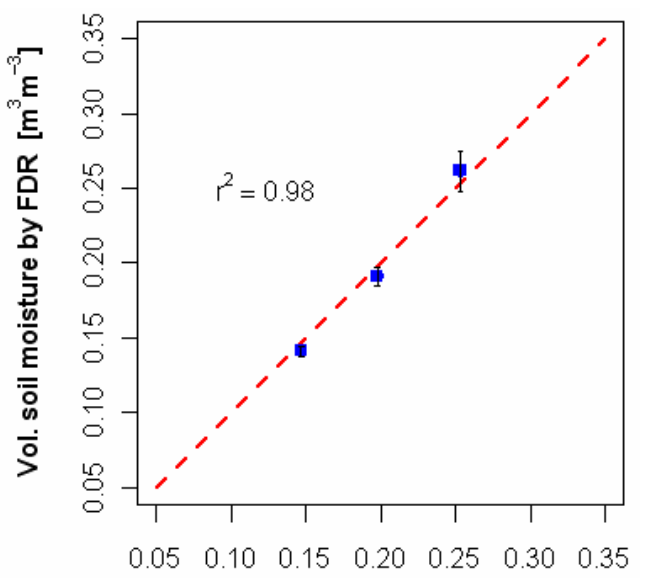

Vol. soil moisture by CRS $\left[\mathrm{m}^{3} \mathrm{~m}^{-3}\right]$

Fig. 6. Calibration of the CRS-1000: (left) calibrated function of soil moisture estimation by ground albedo neutrons (Eq. 1) and (right) correlation between soil moisture measured by CRS-1000 and measured by MR2 probes, where each data point represents the mean value of each calibration period.
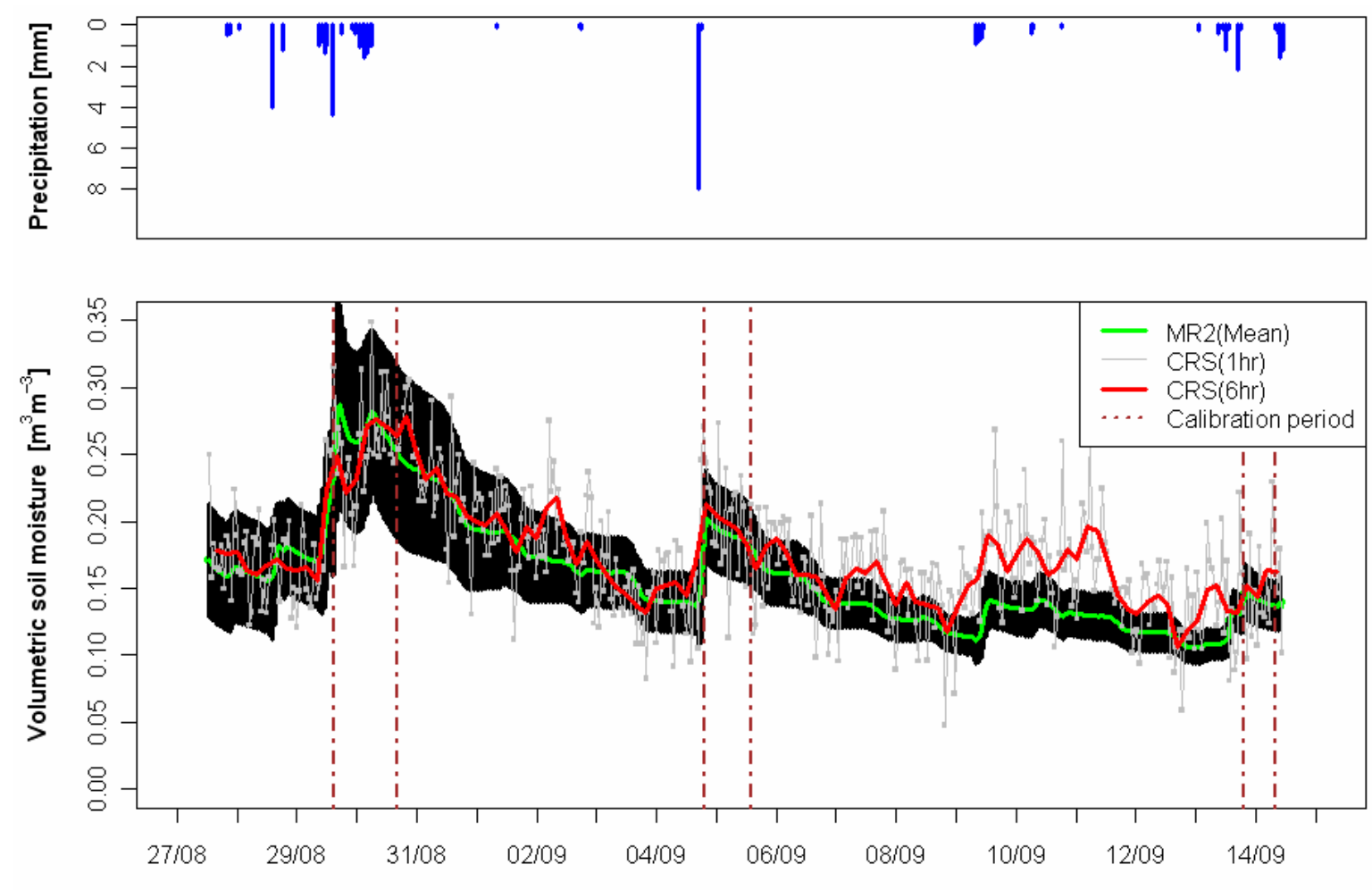

Day of the year 2010

Fig. 7. Soil moisture inferred by the GANS method plotted for a period of cropped field condition. Upper graph: hourly precipitation time series data measured in ATB weather station. Lower graph: soil moisture time series data measured by MR2 probes (spatial mean hourly value in green and one standard deviation in black band) and CRS-1000 (1-h estimations and 6-h moving average in gray and red colors, respectively). The three periods used for calibration of CRS-1000 are shown between vertical dashed lines. 
this information was included in the neutron transport simulations performed by these authors. Therefore, Eq. (1) might be restricted to similar counter specifics.

The values of fitting parameters derived for our field site did not coincide with values reported by Desilets et al. (2010). They reported values of $0.0808,0.372$ and 0.115 for the fitting parameters $a_{0}, a_{1}$ and $a_{2}$, respectively. These values were derived by neutron flux simulations for a generic pure silica soil matrix $\left(\mathrm{SiO}_{2}\right)$ and successfully applied for measurements at a location in Lewis Springs, Arizona, USA $\left(31.562^{\circ} \mathrm{N} 110.140^{\circ} \mathrm{W}\right.$, WGS84, $1233 \mathrm{~m}$ a.s.l.). For the fitting parameters $a_{0}$ and $a_{1}$ identical values cannot be expected, just because of the dependence on the reference dry condition used for normalization (see above). For the third fitting parameter, $a_{2}$, offsetting the minimum soil moisture, a dependence on site soil conditions or detector characteristics would not be surprising.

Thus, the mathematical relation between counting rates of ground albedo neutrons and soil moisture seems applicable, as supported by the good fit of data measured at our field site. Moreover, it seems possible to calibrate at a specific site using independent soil moisture measurements from at least three short time periods. The calibrated parameters can be applied also for soil moisture observations at other times and possibly at similar locations (e.g. at the same hillslope or small catchment with similar soil and land use characteristics), if the same counter type is used. However, transferability of calibration parameters to other locations is still an open question to be evaluated in further investigations.

In the following we report how we tested the CRS-1000 soil moisture measurements during the complete observation period in summer, and also during a winter period with snow cover. In both periods, parameters calibrated were not changed anymore.

\subsection{Test period during summer}

Applying these fitting parameters, soil moisture values derived from hourly ground albedo neutron counts are shown in Fig. 7. A good agreement was observed between time series of soil moisture data by CRS- 1000 and mean soil moisture from the MR2s located in the CRS-1000 footprint. Furthermore, the temporal patterns of soil moisture inferred from MR2s and CRS-1000 are similar, despite their different measurement volumes. Mainly, the GANS-derived soil moisture pattern was inside a range of one standard deviation of MR2s, except in two periods: (i) between 2 September 2011 00:00 LT and 2 September 2011 14:00 LT, and (ii) between 9 September 2011 11:30 LT and 11 September 2011 11:30 LT. Values in this first period fall into a range of two standard deviations of MR2 average mean values. However, during the second period there was a clear overestimation of soil moisture by CRS-1000 compared to MR2 values, longer and more than to be expected by statistical deviations. The reason for this probably is not a measurement error of the
MR2, but from the CRS-1000. However, an easy explanation could not be found and requires further research. After this period, the soil moisture measurements of CRS-1000 decreased again to the level of the MR2 values and responded properly to precipitation events.

Overall, the RMSE between hourly soil moisture values by CRS-1000 and spatial mean hourly values of soil moisture from MR2s was $0.039 \mathrm{~m}^{3} \mathrm{~m}^{-3}$ for the complete cropped field period. This RMSE is similar to the accuracy (cf. Sect. 2.2) of CRS-1000 (0.033) expected from a mean counting rate of 918 ground albedo neutrons per hour.

Furthermore, the GANS method responded well and quickly to precipitation events, as neutron counting rates decreased during precipitation events and stayed lower afterwards; thus GANS-derived soil moisture values increased for those periods as they should (e.g. after events 29 September 2010 and 4 September 2010). However, when CRS1000 data were smoothed with a six-hour moving average, to compensate for the statistical variability of neutron counting rates, fast changes of soil moisture may not be reflected perfectly. For example, the CRS-1000 estimations resulted in an increase of soil moisture a few hours $(\sim 6-7 \mathrm{~h})$ before precipitation actually occurred (e.g. events 8 September 2010 06:00 LT with $0.9 \mathrm{~mm}$ and 12 September 2010 23:00 LT with $0.3 \mathrm{~mm})$.

\subsection{Test period during winter with periods of snow cover}

After harvest of corn, the CRS-1000s were operated at the field site again by end of November 2010. The CRS-1000 data retrieved were used for assessing the difference to the cropped field of the summer period and to test for the impact of snow cover. Values in different depths during the winter period were similar and for a consistent interpretation between summer and winter campaign we used only values of $5 \mathrm{~cm}$ depth (Fig. 8). This winter had an early cold period with snow fall. Classical soil moisture sensors, MR2 probes, could not provide a true measurement of the total soil moisture during parts of the winter period with freezing conditions. Since the classical devices used in this study actually measure the bulk dielectric constant of the soil surrounding the probe, a decrease of MR2 signal under freezing conditions could be expected. The soil's bulk dielectric constant is dominated by the dielectric constant of the liquid water (81 at $20^{\circ} \mathrm{C}$ ), as the dielectric constants of other soil constituents are much smaller; e.g. soil minerals range between 3 and 5 , frozen water is about 4 , and air is about 1 (Jones et al., 2002). Therefore, a change of states from unfrozen soil moisture to frozen soil moisture causes significant changes of soil's bulk dielectric constant. Moreover, we observed that when air temperature (measured in CRS-1000) falls below $0{ }^{\circ} \mathrm{C}$, electrical output of MR2s sharply decreased, and then for negative air temperatures stayed below the usual range of 200 to $850 \mathrm{mV}$, observed under cropped and bare conditions. 

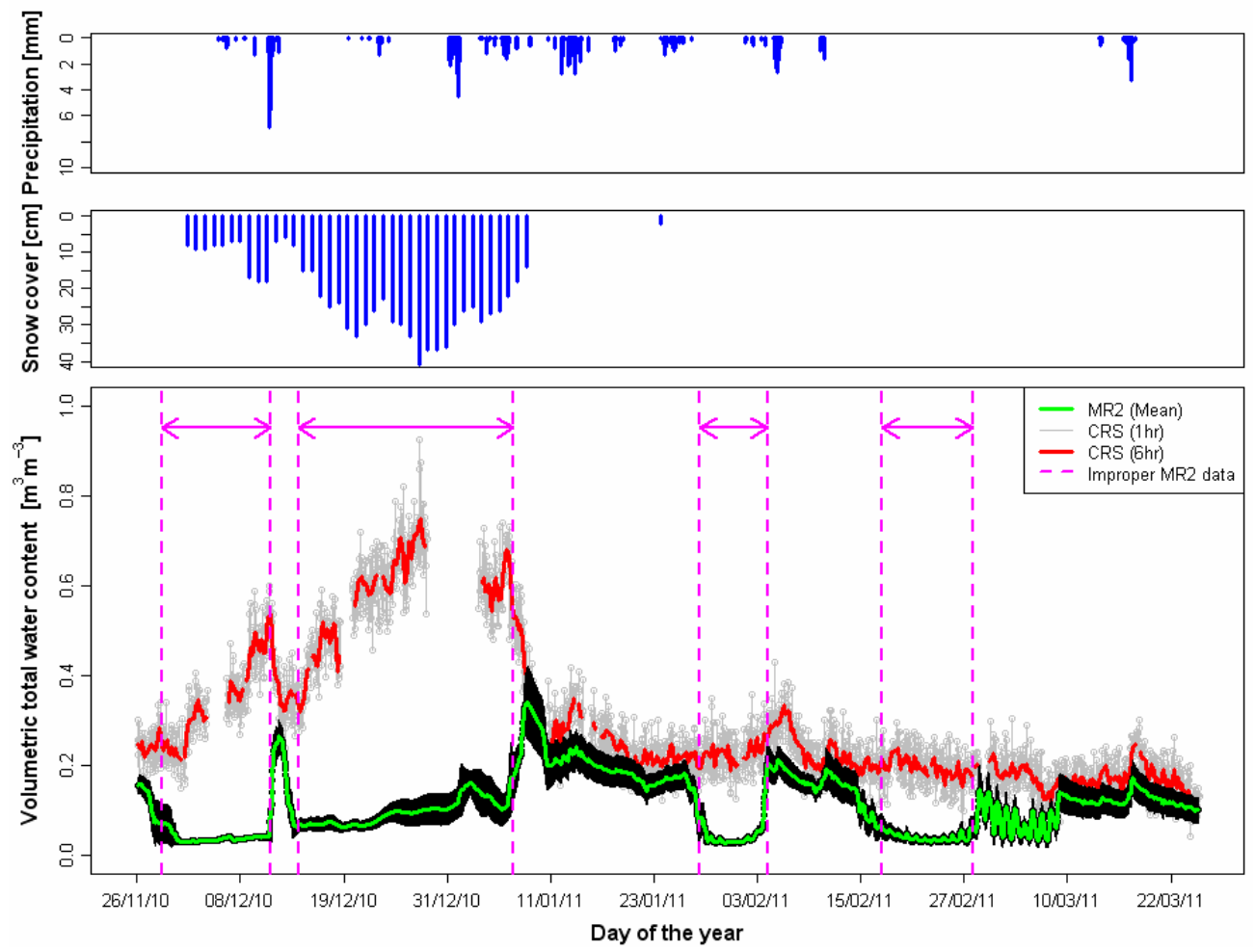

Fig. 8. Total volumetric water content (soil moisture and snow water) measurement by GANS method during the winter period. Two upper graphs: hourly precipitation $(\mathrm{mm})$ in ATB weather station and daily snow cover in PIK weather station. Lower graph: soil moisture time series data measured by MR2 probes (spatial mean hourly value in green and its standard deviation in black band) and CRS-1000 estimations (1-h estimations and 6-h moving average in gray and red colors, respectively). Periods where MR2 did not work properly due to low soil temperature conditions, are shown between vertical dashed lines.

Overall, we found quite good correlation between air temperature and functionality of MR2 probes (not shown) in order to identify periods where MR2s data could be used. Thus, these periods when MR2 probes were not giving real soil moisture values are marked with an arrow between vertical dashed lines in Fig. 8. In the intermediate periods of varying length the MR2 data seem to reflect realistic soil moisture conditions, except a period of one week in the beginning of March showing strong fluctuations.

In this winter period the CRS-1000 calibration via Eq. (1) with soil moisture data from cropped-field conditions was applied without modifications. Therefore, the CRS-1000 derived data could be tested for these bare field conditions, including periods with and without snow cover. During periods of bare soil without snow cover, soil moisture by CRS-1000 reproduced well the values observed in the field (Fig. 8), as long as the MR2s were able to provide correct data, e.g. mid and end of March. In cold periods without snow cover the GANS method gave plausible values, opposed to the MR2, e.g. for the period end of January to the first days of February. It also showed an increased response to precipitation (not resulting in snow cover). Moreover, CRS-1000 measurements of soil moisture were unaffected by sharp drops of air temperature.
Because the MR2s did not properly estimate soil moisture under low temperatures, estimations of CRS-1000 were also validated with results from a fifth soil sampling campaign (Table 2). In this campaign, mean soil moisture was $0.238 \mathrm{~m}^{3} \mathrm{~m}^{-3}$ with a standard deviation of $0.014 \mathrm{~m}^{3} \mathrm{~m}^{-3}$. This is comparable to the areal mean soil moisture of $0.22 \mathrm{~m}^{3} \mathrm{~m}^{-3}$ estimated by means of the GANS method (averaged over the time interval required for the sampling campaign).

In the period when bare soil was covered with snow, neutron counting rates were significantly lower, thus Eq. (1) predicted higher values of $\theta$. Such soil moisture values inferred by GANS method have to be seen as a measurement of the water mass stored in and on the soil in the footprint of the CRS-1000. Nominal soil moisture values derived for these periods exceed porosity values of loamy sand $(0.38)$ in the field. This over-estimation of soil moisture reflects the additional moderation of hydrogen mass in snow, as has to be expected (Kodama et al., 1979), and requests a different interpretation of these nominal soil moisture values. 


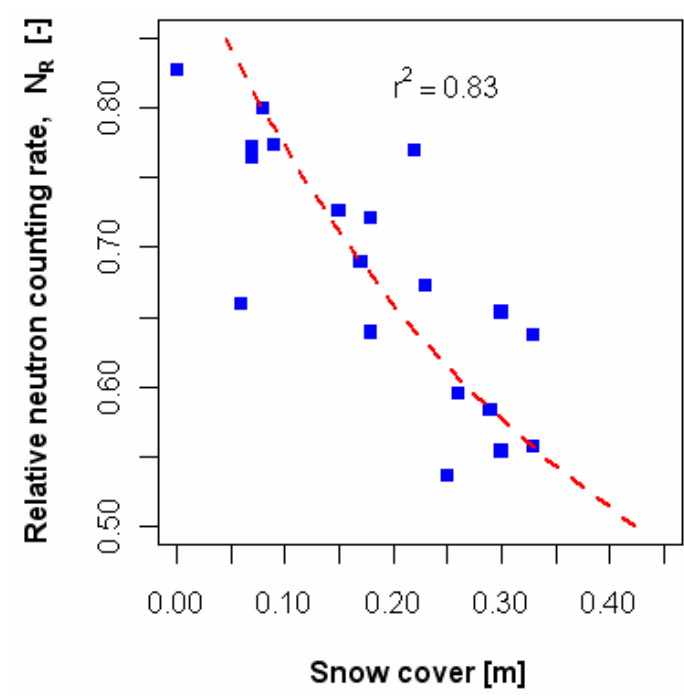

Fig. 9. Normalized daily neutron counting rate $\left(N_{R}\right)$ versus daily snow cover in PIK weather station (Telegrafenberg-Potsdam, Germany).

Normalized neutron counting rates and snow cover data, both as a daily average, suggest that these two could well be related with the calibration curve based on Eq. (1) as shown in Fig. 9. This is in agreement with previous studies of Kodama et al. (1979) and Kodama (1984). In Bornim, lower values of $N_{R}$ were measured for higher snow cover. Maximum and minimum daily snow covers of $41 \mathrm{~cm}$ and $8 \mathrm{~cm}$ corresponded to $N_{R}$ values of 0.47 and 0.80 (daily integration), respectively.

The presence of snow modifies the energies of the neutrons detected, as can be seen clearly in Fig. 3. However, we have not applied a procedure to distinguish between snow moderated and non-snow moderated neutrons, though this could be aimed for in principle. Instead, we take this shift as indication of the impact of snow and otherwise limit our interpretation to nominal soil moisture, which represents the combination of real soil moisture (possibly frozen) and snow water mass equivalent on the soil surface, as discussed above.

When snow started to melt neutron counting rates increased resulting in a steep drop of (nominal) soil moisture until 10 January 2011, when there was no more snow cover on the field. $N_{R}$ values were higher again $(0.72)$ and therefore measurements by CRS- 1000 corresponded again to soil moisture measurements by MR2.

\section{Summary and conclusions}

The work presented has tested the novel cosmic-ray neutron sensing methodology, especially in a new geographical context that may allow for the application of the method in investigations of local soil water balance and catchment hydrology. Furthermore, an application procedure was explored that now could be adopted by others relatively easily for measuring integral soil moisture at intermediate spatial scales.

An operational procedure suggested for application of integral soil moisture measurements on farmland via sensing of ground albedo neutrons, similar to the one used, in summary is:

1. selection of field site location with a $100-300 \mathrm{~m}$ radius with relatively homogeneous soil, vegetation, and relief;

2. installation of a (commercially available) neutron counter, such as a CRS-1000, on a pole with a height of around $1.5 \mathrm{~m}$, best with a moderated and a bare counter, data logger, solar panel, air humidity and temperature measurement and possibly remote data transfer;

3. monitoring site specific soil moisture data in periods of a few days covering at least one dry period and three periods varying between medium wet to wet conditions; use these data for calibration of ground albedo neutron values on the basis of Eq. (1) by adapting the three fitting parameters after correcting neutron counting rates for air pressure variations;

4. derivation of integral soil moisture values on hourly basis, with possible subsequent accumulation or smoothing;

5. observation of snow cover or at least checking the relative difference of counts in moderated and bare counters for $N_{\mathrm{f}}$ values shifted to values outside the bare-field values; possibly use a relation as shown in Fig. 9 to identify count rates influenced by snow cover, if distinguishing between snow and soil water is desired.

Results show that the cosmic-ray neutron method, more precisely ground albedo neutron sensing (GANS), can be successfully applied also for agricultural fields, even at low altitudes where neutron counting rates are lower than in highlands. This inherent disadvantage of lowland applications limits the temporal resolution and implies that an integration period of several hours, or an equivalent smoothing window, are needed to obtain results without too much statistical variability.

Times series of precipitation in comparison with GANS soil moisture values show overall an excellent response of the GANS method to these hydrological events, also smaller precipitation amounts. These observations are in agreement with Kodama's measurements (1985). The GANS-derived soil moisture values are consistent with other measurements in the first $10 \mathrm{~cm}$ of topsoil, but shall also reflect water somewhat deeper than that. There may be short periods of a few days, when soil moisture derived via GANS exhibit a systematic deviation, e.g. observed once in this study between 9 and 11 September 2010, with a shift towards higher values of soil moisture by about $0.05 \mathrm{~m}^{3} \mathrm{~m}^{-3}$. Such shifts might be caused by small changes in incoming primary cosmic ray intensity, 
local air pressure differences or heavy cloud cover. However, this will have to be investigated further. Furthermore, investigations will be needed to specify the real extension of the horizontal footprint for different conditions, e.g. vegetation or topography, as well as how actual soil moisture distribution with depth affects the GANS count rates and vertical albedo neutrons' penetration depth.

Another aspect is the influence of hydrogen stored in other forms besides soil moisture such as water in soil materials or plant roots, carbohydrates, aboveground biomass water or snow. There may be an influence of bound water and carbohydrates in soil which may impact the values of fitting parameters; however, these will not cause a systematic deviation of calibrated soil moisture values. Also, aboveground crop biomass seems not to lead to significant changes in GANS-derived soil moisture values and therefore, biomass of agricultural crops does not necessarily need to be accounted for explicitly in applications of the ground albedo neutron sensing method. However, other vegetation cover, for example trees, probably may have more substantial impact on neutron counting rates and therefore, derived soil moisture values.

Snow cover of the soil has a major influence on neutron counting rates, shifting the nominal soil moisture values easily to more than double or even triple of the real soil moisture values. Since there is good inverse relation with snow height and additionally a shift towards relatively more counts in the bare than the moderated CRS-1000 counter, it could be possible to subtract the snow water mass contribution or even use it to estimate snow height (or snow water equivalent). Moreover, the CRS-1000 was giving reliable values of soil moisture also for periods of freezing conditions without snow cover, opposed to the measurements with MR2 failing in these periods. The use of this methodology to detect snow condition is promising, however further investigation is needed to evaluate a possible quantification procedure.

Overall, this study suggests that the GANS methodology, based on aboveground neutron counting, can successfully be applied at agricultural fields, also in lowlands, provided that similar or higher counting rate levels can be recorded. Nevertheless, methodological improvements will be required. In general, the GANS method has the potential to become a worthwhile and not too expensive extension of soil hydrological measurement methods. It lends itself to extended monitoring as well as shorter-period observations due to the relatively simple installation and mobility. This data could be a valuable input for the observation of hydrological water balances and especially the hydrological modeling of small to medium catchments.

\section{Appendix A}

\section{Transformation of calibration function}

This appendix provides a transformation approach to adapt the calibration function with already fitted parameters to other reference conditions, e.g. drier ones, than those used so far for normalizing neutron count rates. This can be done a posteriori at any time, and without changes to the evaluated soil moisture values, provided that the calibration function is transformed as described in the following.

Count rates for normalization are preferably taken from a period with relatively dry conditions, and corresponding count rates and atmospheric pressure are named $N_{\text {dry_raw }}$ and $P_{\text {dry }}$, respectively. When a count rate for a different period shall be used for normalization $\left(N_{\text {dry_raw }}^{\prime}\right)$ it goes along with a different local atmospheric pressure $\left(P_{\mathrm{dry}}^{\prime}\right)$ during that period. The calibration function, Eq. (1), can be transformed and updated to the use of counting rates with new normalization. For the transformation procedure, two factors $\alpha$ and $\gamma$ for neutron count rates (Eq. A1) and atmospheric pressure (Eq. A2), respectively, are defined as follows:

$N_{\text {dry_raw }}^{\prime}=\alpha \cdot N_{\text {dry_raw }}$

$P_{\text {dry }}^{\prime}=\gamma \cdot P_{\text {dry }}$

Local corrections of neutron count rates by atmospheric pressure is applied as described in Eq. (2)

$N_{\text {dry }}^{\prime}=N_{\text {dry_raw }}^{\prime} \cdot e^{\beta\left(P_{\text {dry }}-P_{\text {mean }}\right)}$

Inserting Eq. (A1) in Eq. (A3) gives

$N_{\text {dry }}^{\prime}=\alpha \cdot N_{\text {dry_raw }} \cdot e^{\beta\left(P_{\text {dry }}^{\prime}-P_{\text {mean }}\right)}$

Re-arranging the exponential term yields

$N_{\mathrm{dry}}^{\prime}=\alpha \cdot N_{\text {dry_raw }} \cdot e^{\beta\left(P_{\mathrm{dry}}-P_{\text {mean }}\right)} \cdot e^{\beta\left(P_{\mathrm{dry}}^{\prime}-P_{\mathrm{dry}}\right)}$

Since $N_{\text {dry }}=N_{\text {dry_raw }} \cdot e^{\beta\left(P_{\text {dry }}-P_{\text {mean }}\right)}$, Eq. (A4) can be written as

$N_{\mathrm{dry}}^{\prime}=\alpha \cdot N_{\mathrm{dry}} \cdot e^{\beta\left(P_{\mathrm{dry}}^{\prime}-P_{\mathrm{dry}}\right)}$

Equation (A5) specifies how old and new normalized counting rates are related, where $\alpha$ and $e^{\beta\left(P_{\mathrm{dry}}^{\prime}-P_{\mathrm{dry}}\right)}$ are constants. Then, if Eq. (A2) is inserted in Eq. (A5) and constants are re-grouped, we get

$$
\begin{aligned}
N_{\mathrm{dry}}^{\prime}= & \left(\alpha \cdot e^{\beta\left(\gamma \cdot P_{\mathrm{dry}}-P_{\mathrm{dry}}\right)}\right) \cdot N_{\mathrm{dry}}= \\
& \left(\alpha \cdot e^{\beta \cdot P_{\mathrm{dry}}(\gamma-1)}\right) \cdot N_{\mathrm{dry}}
\end{aligned}
$$

Because of parameters inside the parenthesis are all constants, the expression in the parenthesis can be named by another constant $\lambda$ yielding the following relation

$N_{\mathrm{dry}}^{\prime}=\lambda \cdot N_{\mathrm{dry}}$ 
In the calibration function, Eq. (1), relative neutron count rates are used, and the ones used so far can now be related to neutron count rates normalized via the new reference conditions as follows:

$N_{R}=\frac{N}{N_{\text {dry }}}=\lambda \frac{N}{N_{\text {dry }}^{\prime}}$

Replacing this term in the calibrated function Eq. (1) by Eq. (A8) gives

$\rho_{\text {wat }} / \rho_{\mathrm{b}} \theta(N)=\frac{a_{0}}{\frac{N}{N_{\text {dry }}}-a_{1}}-a_{2}=\frac{a_{0}}{\lambda \frac{N}{N_{\text {dry }}^{\prime}}-a_{1}}-a_{2}$

Finally, simplifying Eq. (A9) to

$\rho_{\text {wat }} / \rho_{\mathrm{b}} \theta=\frac{a_{0} / \lambda}{\frac{N}{N_{\text {dry }}^{\prime}}-\frac{a_{1}}{\lambda}}-a_{2}=\frac{a_{0} / \lambda}{N_{R}^{\prime}-\frac{a_{1}}{\lambda}}-a_{2}$

This demonstrates that this calibration function of a GANS probe may be adjusted during on-going measurements or even retrospectively, if besides using the differently normalized neutron counting rates the parameters $a_{0}$ and $a_{1}$ in the calibration function are divided by the constant $\lambda$.

Acknowledgements. This study was partly funded by the Potsdam Graduate School (POGS) and the German Ministry of Education and Research (BMBF) as part of IPSWaT (International Postgraduate Studies in Water Technologies). The research was supported by the Helmholtz Centre for Environmental Research-UFZ and TERENO (Terrestrial Environmental Observatories) by providing the cosmic ray sensors used at the field site. Furthermore, we thank the Leibniz Institute for Agricultural Engineering Potsdam-Bornim (ATB) for their support, especially Robin Gebbers for conveying the experimental site and supporting our field work and Jürgen Kern for providing weather station data.

We also acknowledge the NMDB database (www.nmdb.eu), founded under the European Union's FP7 programme (contract no. 213007) for providing data, namely from KIEL, LMKS, JUNG and ROME stations.

We also thank Heye Bogena (FZJ, Jülich, Germany), Hannes Flühler (ETH Zürich, Switzerland), the editor HarrieJan Hendricks Franssen (RWTH Aachen \& FZJ, Germany) and one anonymous reviewer for their critical and helpful review comments.

Edited by: H.-J. Hendricks Franssen

\section{References}

Bachelet, F., Balata, P., Drying, E., and Iucci, N.: Attenuation Coefficients of the Cosmic-Ray Nucleonic Component in the Lower Atmosphere, IL Nuovo Cimento, XXXV, 1, 1965.

Barrett, B. W., Dwyer, E., and Whelan, P.: Soil Moisture Retrieval from Active Spaceborne Microwave Observations: An Evaluation of Current Techniques, Remote Sensing, 1, 210-242, doi:10.3390/rs1030210, 2009.

Beverwijk, A.: Particle size analysis of soils by means of the hydrometer method, Sedimentary Geol., 1, 403-406, 1967.
Bogena, H. R., Herbst, M., Huisman, J. A., Rosenbaum, U., Weuthen, A., and Vereecken, H.: Potential of wireless sensor networks for measuring soil water content variability, Vadose Zone J., 9, 1002-1013, 2010.

Christiansen, L., Lund, S., Andersen, O. B., Binning, P. J., Rosbjerg, D., and Bauer-Gottwein, P.: Measuring gravity change caused by water storage variations: Performance assessment under controlled conditions, J. Hydrol., 402, 60-70, 2011.

Desilets, D., Zreda, M., and Ferré, T. P. A.: Nature's neutron probe: Land surface hydrology at an elusive scale with cosmic rays, Water Resour. Res., 46, W11505, doi:10.1029/2009WR008726, 2010.

Entekhabi, D., Njoku, E. G., O’Neill, P. E., Kellogg, K. H., Crow, W. T., Edelstein, W. N., Entin, J. K., Goodman, S. D., Jackson, T. J., Johnson, J., Kimball, J., Piepmeier, J. R., Koster, R. D., Martin, N., McDonald, K. C., Moghaddam, M., Moran, S., Reichle, R., Shi, J. C., Spencer, M. W., Thurman, S. W., Tsang, L., and Van Zyl, J.: The Soil Moisture Active Passive (SMAP) Mission, P. IEEE, 98, 704-716, 2010.

Garre, S., Javaux, M., Vanderborght, J., Pages, L., and Vereecken, H.: Three-Dimensional Electrical Resistivity Tomography to Monitor Root Zone Water Dynamics, Vadose Zone J., 10, 412424, 2011.

Gebbers, R., Lück, E., Dabas, M., and Domsch, H.: Comparison of instruments for geoelectrical soil mapping at the field scale, Near Surf. Geophys., 9, 179-190, 2009.

Graeff, T., Zehe, E., Schlaeger, S., Morgner, M., Bauer, A., Becker, R., Creutzfeldt, B., and Bronstert, A.: A quality assessment of Spatial TDR soil moisture measurements in homogenous and heterogeneous media with laboratory experiments, Hydrol. Earth Syst. Sci., 14, 1007-1020, doi:10.5194/hess-14-10072010, 2010.

Hess, W. N., Canfield, E. H., and Lingenfelter, R. E.: Cosmic-Ray Neutron Demography, J. Geophys. Res., 66, 665-677, 1961.

Horsley, A.: Neutron cross sections of hydrogen in the energy range $0.0001 \mathrm{eV}-20 \mathrm{MeV}$, Nucl. Data Sheets, 2, 243-262, doi:10.1016/S0550-306X(66)80005-8, 1966.

Huisman, J. A., Hubbard, S. S., Redman, J. D., and Annan, A. P.: Measuring Soil Water Content with Ground Penetrating Radar: A Review, Vadose Zone J., 2, 476-491, 2003.

Kerr, Y. H., Waldteufel, P., Wigneron, J.-P., Martinuzzi, J., Font, J., and Berger, M.: Soil moisture retrieval from space: the Soil Moisture and Ocean Salinity (SMOS) mission, IEEE T. Geosci. Remote, 39, 1729-1735, 2001.

Kodama, M.: Continuous monitoring of snow water equivalent using cosmic ray neutrons, Cold Reg. Sci. Technol., 3, 295-303, 1980.

Kodama, M.: An introduction to applied cosmic ray physics, Jpn J. Appl. Phys., 23, 726-728, 1984.

Kodama, M., Nakai, K., Kawasaki, S., and Wada, M.: An application of cosmic-ray neutron measurements to the determination of the snow-water equivalent, J. Hydrol., 41, 85-92, 1979.

Kodama, M., Kudo, S., and Kosuge, T.: Application of atmospheric neutrons to soil moisture measurement, Soil Sci., 140, 237-242, 1985.

Krane, K.: Introductory Nuclear Physics, Wiley \& Sons, New York, 1988.

Leirião, S., He, X., Christiansen, L., Andersen, O. B., and BauerGottwein, P.: Calculation of the temporal gravity variation from 
spatially variable water storage change in soils and aquifers, J. Hydrol., 365, 302-309, 2009.

Neutron Monitor Database: available at: http://www.nmdb.eu/, last access: 4 July 2011.

Oswald, S. E., Menon, M., Carminati, A., Vontobel, P., Lehmann, E., and Schulin, R.: Quantitative Imaging of Infiltration, Root Growth, and Root Water Uptake via Neutron Radiography, Vadose Zone J., 7, 1035-1047, 2008.

Parker, E. N.: The passage of energetic charged particles through interplanetary space, Planet. Space Sci., 13, 9-49, 1965.

Rinard, P.: Neutron interactions with matter, Los Alamos Technical Report, available at: http://www.fas.org/sgp/othergov/doe/ lan1/lib-www/la-pubs/00326407.pdf, 2009.

Robinson, D. A., Campbell, C. S., Hopmans, J. W., Hombuckle, B. K., Jones, S. B., Knight, R., Ogden, F., Selker, J., and Wendroth, O.: Soil Moisture Measurement for Ecological and Hydrological Watershed-Scale Observatories: A Review, Vadose Zone J., 7, 358-389, 2008.

Saatchi, S. S., Houghton, R. A., Dos Santos Alvalá, R. C., Soares, J. V., and Yu, Y.: Distribution of aboveground live biomass in the Amazon basin, Glob. Change Biol., 13, 816-837, 2007.

Schwank, M., Wiesmann, A., Werner, C., Mätzler, C., Weber, D., Murk, A., Völksch, I., and Wegmüller, U.: ELBARA II, an LBand Radiometer System for Soil Moisture Research, Sensors, 10, 584-612, 2009.
Sears, V. F.: Neutron scattering lengths and cross sections, Neutron News, 3, 26-37, 1992.

Shuttleworth, W. J., Zreda, M., Zeng, X., Zweck, C., and Ferré, T. P. A.: The COsmic-ray Soil Moisture Observing System (COSMOS): a non-invasive, intermediate scale soil moisture measurement network., BHS Third International Symposium, Managing Consequences of a Changing Global Environment., Newcastle, 2010.

Tapley, B. D., Bettadpur, S., Ries, J. C., Thompson, P. F., and Watkins, M. M.: GRACE Measurements of Mass Variability in the Earth System, Science, 305, 503-505, 2004.

Tumlinson, L. G., Liu, H., Silk, W. K., and Hopmans, J. W.: Thermal Neutron Computed Tomography of Soil Water and Plant Roots, Soil Sci. Soc. Am. J., 72, 1234-1242, 2008.

Western, A. W., Grayson, R. B., and Blöschl, G.: Scaling of soil moisture: A hydrologic perspective, Annu. Rev. Earth Pl. Sc., 30, 149-180, 2002.

Wu, W. and Dickinson, R. E.: Time Scales of Layered Soil Moisture Memory in the Context of Land-Atmosphere Interaction, J. Climate, 17, 2752-2764, 2004.

Zreda, M., Desilets, D., Ferré, T. P. A., and Scott, R. L.: Measuring soil moisture content non-invasively at intermediate spatial scale using cosmic-ray neutrons, Geophys. Res. Lett., 23, 949-952, 2008. 